\title{
Repeat variation of electrocardiogram, blood pressure, and blood cholesterol within one hour and six months ${ }^{1}$
}

\author{
Ernst Simonson and Ancel Keys \\ From Laboratory of Physiological Hygiene, Stadium Gate 27, University of Minnesota, \\ Minneapolis, Minnesota 55455, U.S.A.
}

The intraindividual repeat variation of the conventional 12-lead electrocardiogram, of blood pressure, and of blood cholesterol was determined in 27 middle-aged healthy men with an interval of one hour and six months. In 7 of I 7 analysed electrocardiographic items the variation within six months was significantly greater than that within one hour; in Io items, the variation was not significantly different. Blood pressure varied as much within one hour as within six months, while the intraindividual variation of serum cholesterol was significantly greater for the sixmonth period. The intraindividual variation, expressed as the coefficient of variation, was greater for the electrocardiogram than for either blood pressure or cholesterol. There were large differences between various electrocardiographic items in the repeat variation. There was high intraclass correlation of most items analysed, but no significant covariation between electrocardiographic item vs. blood pressure or cholesterol.

Variation (inter- and intraindividual) of any function is a fundamental characteristic of that function. While reliable information about the interindividual variation of the electrocardiogram is available, quantitative information about spontaneous (repeat) variation is scanty. Such information would be valuable, if not essential, for interpretation of serial electrocardiograms in clinical routine.

Some information about repeat variation of the electrocardiogram within one or several years is potentially available from longitudinal epidemiologidal studies such as the Framingham Project (Kannel et al., 1964); the Minneapolis CVD Project (Keys et al., 1963); and the International Cooperative Study on Cardiovascular Epidemiology (Keys et al., 1967).

In cardiovascular patients, particularly while in hospital, electrocardiograms are taken at shorter intervals, within one or several days or weeks, and occasionally, in more critical situations, within the same day. In the absence of reliable information on normal intraindividual variation the interpretation of electrocardiographic changes in serial electro-

Received 16 February 1970.

${ }^{2}$ Supported in part by NIH grants. Laboratory of Physiological Hygiene, University of Minnesota, and Mt. Sinai Hospital, Minneapolis, Minnesota. cardiograms is arbitrary to some degree unless the changes are large.

Quantitative information about intraindividual variation and the electrocardiogram was presented by Simonson, Brozek, and Keys (1949). In 12 young men, three standard and three chest/-left foot leads were repeated on II occasions over a period of two months with measurement of 35 electrocardiographic items. The intraindividual variation for an average interval of three to four days was quite different for the various electrocardiographic items which were classed in five categories as to the extent of repeat variation, according to the coefficient of variation

$$
\left(r^{\prime}{ }_{c}=\frac{\text { intraindividual variance }}{\text { interindividual variance }}\right) \text {. }
$$

Variation of the position of chest electrodes was minimized by marking the spots on the skin with intracutaneous dye injection. The repeat variation of the electrocardiogram of ambulatory patients with coronary heart disease (in the absence of acute coronary insufficiency) was significantly greater than that of age-matched healthy persons (Simonson, 1955). Thus, increased variation, inside or outside normal range limits, may be a sensitive index for early or mild myocardial involvement. 
To provide more information on intraindividual variation we have studied variation within one hour, in controlled relaxation, and for the broader perspective of electrocardiogram variability as compared with other variables; in addition, we investigated $I$ hour and 6 months repeat variation of two functions which have significance for the management of patients with coronary heart disease, namely arterial blood pressure and blood cholesterol. These data are presented for the purpose of comparison of variation within the same sample only; a detailed review of variation of blood pressure and cholesterol would exceed the scope of this communication.

\section{Methods and subjects}

Twenty-seven healthy men from 40 to 65 years of age (mean 52.2) volunteered as subjects. Their occupation was sedentary. All men had participated in another experimental series and were familiar with the laboratory and the methods used. The conventional 12-lead electrocardiogram, blood pressure, and a blood sample were taken in the basal condition after an initial rest period of Io to I5 minutes. The procedure was repeated after a one-hour interval of relaxation. The records after the six-month interval were taken in the basal condition. The electrocardiograms were taken with a direct-writing Sanborn recorder in arrested mid-respiratory position. The amplitude measurements were averaged from the maximum and minimum complexes in any given lead (the differences, however, were small) and corrected for the standard deflection to $\mathrm{I} \mathrm{mm} .=0.1 \mathrm{mV}$.

In the one-hour period the subjects relaxed and most of them in the supine position read light literature such as popular magazines. Physical activity and reading professional literature were not allowed. The subjects were first investigated in June, and came back for the one-hour relaxation period in December. Thus, seasonal variation may be involved in the six-month repeat variation.

In the recordings at an interval of one hour, the spots for chest electrode positions were identical, but in the repetitions six months later, it was not possible to assure identity of the electrode positions. For a precise comparison of one-hour and six months variation, it would have been desirable to mark the electrode position also for the six months period, but this is not practically possible. Marks with indelible ink will last about 3 to 4 days, and marks with intracutaneous injection of India ink will last about 5 to 6 weeks. Our procedure is closer to the usual clinical situation, where pencil marks for electrode position are visible for several hours, but not for longer intervals.

\section{Statistical evaluation}

Both inter- and intraindividual variability were calculated. Two methods were used for comparison of one-hour and six months variation, the coefficient of variation (CV: ratio of $\Delta S D$ of the mean repeat changes $\Delta M \times 100$ : mean initial value $M)$. Thus, $C V$ shows the repeat variation $(\Delta S D)$ as a percentage of the initial value $(M)$. CV would be meaningless for angles and was not calculated for the QRS and T axes. We also used the coefficient of consistency

$$
\mathbf{r}_{0}^{\prime}=\mathbf{I}-\frac{\text { intraindividual variance }}{\text { interindividual variance }} \text {. }
$$

The statistical basis for $\mathbf{r}^{\prime}{ }$ was described in the earlier study (Simonson et al., I949).

\section{Results}

Electrocardiogram Table I shows the initial means $(M)$, the mean difference of terminal minus initial value $(\Delta M)$, and the standard deviation $(\Delta S D)$ of $\Delta M$, coefficient of variation $C V$, and the coefficient of consistency $\left(\mathbf{r}^{\prime}{ }_{\mathrm{c}}\right)$ of ${ }^{17}$ selected electrocardiographic items, within I hour and within 6 months. The differences between the initial values and the repeat values $(\Delta M)$ are small and not significant except for $\mathrm{R}_{-} \mathrm{V}_{4}, \mathrm{~S}_{2}, \mathrm{~T}_{1}$, and $\mathrm{T}_{2}$ for the hourly variation, and for $R_{2}$ for the 6 months variation. In general, therefore, the intraindividual variation is random.

The repeat variation within one hour is surprisingly large, with a range from II to 75 per cent in the coefficient of variation. As in our previous study (Simonson et al., 1949), the repeat variability of the different items differs greatly: relatively stable items (CV up to $16 \%$ ) are all $R$ waves and the $R R$ interval, grossly unstable items $(\mathrm{CV}>30 \%)$ are $\mathrm{S}-\mathrm{V}_{5}$, $T_{3}$, and $R / S$ ratio in VI. Most items with low repeat variability showed also a low variability in the previous study, except for the RR interval which showed a higher variability in the previous study.

In seven items, the variation within the sixmonths interval exceeded significantly the one-hour variation $\left(R_{1}, R_{2}, R_{5}, S_{4}, S_{5}\right.$, $Q R S$ axis, and $R R$ interval). Variation of the chest electrode position may be a contributing factor for $\mathrm{RV}_{5}, \mathrm{SV}_{4}$, and $\mathrm{SV}_{5}$. However, high CV's are found also for several items of limb leads.

For the evaluation of $r^{\prime}$, Simonson et al. (1949) used an arbitrary scale; $r_{0}^{\prime}>0.9$ was considered very high, from 0.89 to $0.80 \mathrm{high}$, from 0.79 to 0.70 moderate, from 0.69 to 0.60 low, and $<0.60$ very low. Using this scale the $\mathbf{r}^{\prime}$ for variation within one hour is high or very high for all $R$ waves, all $S$ waves, $Q R S$ and $T$ axis and $T_{2}$, low or very low for $R R$ interval and $P R$ interval. There are some discrepancies to the $C V$ values, for instance for $T_{2}$ and $R R$ interval. This is not surprising in view of the basic difference of both criteria. However, in general the agreement is quite good, i.e. 
TABLE I Means $(M)$, mean differences $(\Delta M)$, with standard deviations $(\Delta S D)$, coefficients of variation $(C V)$, and coefficient of consistency $\left(r_{c}^{\prime}\right)$ of various electrocardiographic items within $I$ hour and within 6 months in 27 men

\begin{tabular}{|c|c|c|c|c|c|c|c|c|c|c|}
\hline \multirow[b]{2}{*}{ Item } & \multirow[b]{2}{*}{$\begin{array}{l}\text { Initial } \\
M\end{array}$} & \multicolumn{4}{|l|}{ I hour } & \multirow[b]{2}{*}{$\begin{array}{l}\text { Initial } \\
M\end{array}$} & \multicolumn{4}{|l|}{6 months } \\
\hline & & $\Delta M \dagger$ & $\Delta S D$ & $C V^{\star}$ & $r_{\mathrm{c}}^{\prime}$ & & $\Delta M \dagger$ & $\Delta S D$ & $C V$ & $r_{c}^{\prime} \ddagger$ \\
\hline RI & 6.96 & -0.29 & 0.87 & 12.6 & 0.93 & 6.52 & -0.13 & $I \cdot 33$ & $20 \cdot 4$ & 0.86 \\
\hline $\mathbf{R}_{2}$ & $9 \cdot 40$ & -0.21 & $r \cdot 4 I$ & $15 \cdot 0$ & 0.97 & $9 \cdot 14$ & $-I \cdot I 2 \int$ & $4 \cdot 64$ & $50 \cdot 7$ & 0.67 \\
\hline $\mathbf{R}_{\mathbf{3}}$ & $5 \cdot 39$ & +0.08 & 0.88 & 16.2 & 0.98 & $4 \cdot 74$ & -0.11 & I.05 & $22 \cdot 2$ & 0.98 \\
\hline $\mathrm{RV}_{4}$ & 16.52 & $-I \cdot I 6 S$ & $2 \cdot 30$ & 13.9 & 0.89 & 16.02 & -0.89 & 2.44 & 15.3 & 0.92 \\
\hline $\mathrm{RV}_{5}$ & $15.8 \mathrm{I}$ & $-0.5^{8}$ & 2.08 & $13 \cdot 1$ & 0.92 & $14 \cdot 78$ & 0.11 & $3 \cdot 30$ & $22 \cdot 4$ & 0.83 \\
\hline SI & $I \cdot 75$ & -0.08 & 0.48 & $27 \cdot 7$ & 0.91 & 0.78 & 0.01 & 0.31 & $40 \cdot 0$ & 0.95 \\
\hline$S_{2}$ & $I \cdot 73$ & $-0.27 \S$ & 0.45 & $26 \cdot 1$ & 0.86 & 0.72 & -0.05 & 0.51 & $7 I \cdot I$ & 0.77 \\
\hline$s_{3}$ & 3.68 & -0.04 & I.OI & $27 \cdot 4$ & 0.93 & $\mathrm{I} \cdot 94$ & -0.13 & $I \cdot I I$ & $57 \cdot 3$ & 0.90 \\
\hline $\mathrm{SV}_{4}$ & $5 \cdot 30$ & -0.34 & $I \cdot 2 I$ & $22 \cdot 9$ & 0.91 & $5 \cdot 04$ & 0.24 & $2 \cdot 32$ & $46 \cdot 0$ & 0.73 \\
\hline sv 5 & $2 \cdot 43$ & 0.36 & 0.93 & $38 \cdot 4$ & $0.8 \mathrm{I}$ & $1 \cdot 85$ & 0.17 & I.95 & 105.6 & 0.56 \\
\hline$T_{I}$ & 2.06 & 0.319 & 0.45 & $21 \cdot 8$ & 0.78 & $I \cdot 92$ & -0.27 & 0.40 & 20.9 & 0.87 \\
\hline$T_{2}$ & $2 \cdot 33$ & $-0.15 \delta$ & 0.49 & $20 \cdot 8$ & 0.85 & $2 \cdot 33$ & -0.30 & 0.50 & $21 \cdot 6$ & 0.82 \\
\hline $\mathrm{T}_{3}$ & I.09 & -0.05 & 0.82 & 74.9 & 0.58 & 0.72 & 0.05 & 0.82 & 113.5 & 0.76 \\
\hline $\mathrm{R} / \mathrm{SVI}$ & 0.23 & 0.15 & 0.08 & 35.0 & - & - & - & - & - & - \\
\hline QRS axis ${ }^{\circ}$ & $37 \cdot 2$ & 0.54 & 8.50 & - & 0.97 & $36 \cdot 6$ & $3 \cdot 48$ & 16.82 & - & 0.88 \\
\hline $\mathrm{T}$ axis $^{\circ}$ & 44.7 & 2.50 & $11 \cdot 55$ & - & 0.85 & $40 \cdot 2$ & 1.85 & $15 \cdot 18$ & - & 0.86 \\
\hline $\mathbf{R} \mathbf{R}$ interval & $9 \mathrm{I} \cdot 8$ & $6 \cdot 32$ & 10.40 & II 3 & 0.63 & $9 I \cdot 2$ & 2.52 & 15.86 & $I 7 \cdot 4$ & 0.76 \\
\hline PR interval & $14 \cdot 2$ & 0.60 & $4 \cdot 22$ & $29 \cdot 8$ & 0.46 & 18.9 & 0.03 & $3.4 \mathrm{I}$ & $18 \cdot 0$ & $0.4 \mathrm{I}$ \\
\hline
\end{tabular}

Footnote. All amplitudes are in $0.1 \mathrm{mV}$, all intervals in $\mathrm{I} / \mathrm{I} 00 \mathrm{sec}$.

$\star \mathrm{CV}=\frac{\Delta \mathrm{SD} \times 100}{\text { Init. } \mathrm{M}}$

† Statistical significance of $\Delta M$ (change from initial values): $\oint p=<0.05$.

$\ddagger r^{\prime}{ }_{c}=\mathbf{r}-\frac{\text { intraindividual variance }}{\text { interindividual variance }}$.

low $\mathrm{CV}$ corresponds to high $\mathbf{r}_{\mathrm{c}}^{\prime}$. This is the case also for the six months $\mathrm{CV}$ and $\mathbf{r}_{\text {co }}^{\prime}$, though the few items with discrepancies are not all identical with those for the one-hour variation.

Since statistical comparison of the $\mathbf{r}_{\mathrm{c}}$ for one hour and six months variation (such as $t$ or $\mathbf{F}$ test) is not possible, we used, as in the previous study, an arbitrary scale for comparison; a difference up to $0 \cdot 10$ was considered as little change, from 0.1 to 0.19 moderate change, and $>0.20$ as more pronounced change. Twelve of the 17 items are in the same order of variation (i.e. $<0 \cdot I$ ) for one hour and six months; in two items, $\mathbf{r}_{\mathrm{c}}^{\prime}$ was moderately lower for the six months interval $\left(\mathrm{SV}_{4}, \mathrm{SV}_{5}\right)$, and in one item, $\mathrm{R}_{2}$, it was definitely lower; these items also showed a higher $\mathrm{CV}$ for the six months variation. For $T_{3}$ and the RR interval, $\mathbf{r}_{c}^{\prime}$ was moderately higher.

The intraclass correlation between the initial and terminal values of five selected electrocardiographic items was high except for the $R R$ interval and $R_{2}$ for the six months interval. That is, the subjects who had high values on the first occasion also had high values on the second (Table 2).
Blood pressure; serum cholesterol Table 3 shows the one-hour and six months repeat variation of the systolic and diastolic blood pressure and of serum cholesterol. The repeat $\Delta$ SDs for the blood pressure were not significantly different for both intervals, i.e. in this material the blood pressure varied as much within one hour as within six months. On the other hand, the repeat variation of the serum cholesterol within six months is significantly larger than that within one hour. Table 4 shows the intraclass correlations between initial and terminal values which are high for cholesterol and moderately high for systolic blood pressure (both intervals) and for the diastolic blood pressure for the one-hour interval.

TABLE 2 Intraclass correlation ( $r$ ) between initial and terminal values of five selected electrocardiographic items

\begin{tabular}{llllll}
\hline & $\begin{array}{l}R R \\
\text { initial }\end{array}$ & $R 2$ & $T 2$ & $\begin{array}{l}Q R S \\
\text { axis }\end{array}$ & $\begin{array}{l}T \\
\text { axis }\end{array}$ \\
\hline I hour & $\begin{array}{llll}0.63 \\
\text { months }\end{array}$ & $\begin{array}{l}0.47 \\
0.66\end{array}$ & $\begin{array}{l}0.85 \\
0.81\end{array}$ & $\begin{array}{l}0.97 \\
0.87\end{array}$ & $\begin{array}{l}0.84 \\
0.85\end{array}$ \\
\hline
\end{tabular}


TABLE 3 Means $(M)$, mean differences $(\Delta M)$ with standard deviations $(\Delta S D)$; and coefficient of variation $(C V)$ of systolic and diastolic blood pressure; and blood cholesterol within one hour and within six months $(N=27)$

\begin{tabular}{|c|c|c|c|c|c|c|c|c|c|}
\hline \multirow[b]{2}{*}{$\begin{array}{l}\text { Blood pressure } \\
(\mathrm{mm} . \mathrm{Hg})\end{array}$} & \multicolumn{4}{|l|}{ I hour } & \multicolumn{5}{|c|}{6 months } \\
\hline & $\begin{array}{l}\text { Initial } \\
M\end{array}$ & $\Delta M$ & $\Delta_{\Delta S D}$ & $C V \%$ & $\begin{array}{l}\text { Initial } \\
M\end{array}$ & $\Delta M$ & ${ }^{\Delta} \Delta S D$ & $C V \%$ & $F$ test \\
\hline $\begin{array}{l}\text { Systolic } \\
\text { Diastolic } \\
\text { Cholesterol } \\
\text { (mg./rooml.) }\end{array}$ & $\begin{array}{r}128 \cdot 3 \\
72 \cdot 7 \\
232 \cdot 0\end{array}$ & $\begin{array}{c}2.20 \\
-0.23 \\
4.645\end{array}$ & $\begin{array}{r}12.39 \\
7.55 \\
9.66\end{array}$ & $\begin{array}{l}9 \cdot 66 \\
9 \cdot 47 \\
4 \cdot 17\end{array}$ & $\begin{array}{r}127 \cdot 1 \\
73 \cdot 2 \\
229 \cdot 6\end{array}$ & $\begin{array}{r}1 \cdot 30 \\
-6 \cdot 50 \\
2 \cdot 33\end{array}$ & $\begin{array}{r}9 \cdot 54 \\
6 \cdot 78 \\
26 \cdot 81\end{array}$ & $\begin{array}{r}7 \cdot 50 \\
4 \cdot 14 \\
11 \cdot 68\end{array}$ & $\begin{array}{l}I \cdot 69 \\
I \cdot 23 \\
7 \cdot 675\end{array}$ \\
\hline
\end{tabular}

$S p=\leq 0.05$.

TABLE 4 Intraclass correlation ( $r$ ) between initial and terminal values of systolic and diastolic blood pressure, and of blood cholesterol

\begin{tabular}{llll}
\hline & Systolic & Diastolic & Cholesterol \\
\hline I hour & 0.79 & 0.72 & 0.98 \\
6 months & 0.77 & 0.40 & 0.88 \\
\hline
\end{tabular}

\section{Discussion}

The repeat variation includes the error of measurement and beat-to-beat variation. The error of measurement (Simonson, 196I, Table 7, p. 68) of $R, S$, and $T$ waves, expressed as the coefficient of variation, is of the order of I to 8 per cent; for the PR interval 6 per cent, for the RR interval only 0.27 per cent; the SD for the mean error of measurement of the QRS axis is 4 degrees and for the $T$ axis 5.5 degrees. Consequently, the contribution of the error of measurement is comparatively small. The beat-to-beat variation, calculated for the $R$ wave in lead X (SVEC III and Frank systems) in five beats varied in 4 men between a CV of 0.6 to I.I per cent, and is probably also fairly representative for beat-tobeat variation in the conventional leads (Simonson et al., 1966). The contribution of beat-to-beat variation appears to be small.

Clinical application The 95 per cent range of repeat variation may be estimated from \pm 2 SD in Table $I$, with the reservation that the sample is too small for evaluation of skewness of distribution. Still, the range limits calculated from the SD will be useful for clinical application until a larger sample is available. As an example, Table 5 shows the predicted normal range of variation within the same individual within one hour and six months for nine selected items. Thus, $T_{1}$ and $T_{2}$ may vary spontaneously by $\pm \mathrm{I} \mathrm{mm}$., $R \mathrm{R}$ by $\mathrm{I} \cdot 5$ $\mathrm{mm}, \mathrm{QRS}$ axis by $17^{\circ}$, and $\mathrm{T}$ axis by $23^{\circ}$ spontaneously within one hour. Obviously, variations within this range have no clinical significance, but variations exceeding this range would have significance even if they occurred within the wide range of normal interindividual variation, i.e. within the normal limits as used in clinical electrocardiography. The spontaneous repeat variation in patients with coronary heart disease and abnormal electrocardiogram, but without acute coronary insufficiency, may be expected to be significantly larger (Simonson, 1955). Abnormally increased repeat variation may be an early sign of cardiac disease, before the electrocardiogram becomes frankly abnormal (Simonson, 1955).

Comparison of $\mathrm{CV}$ in Tables $\mathrm{I}$ and 3 shows that the intrinsic repeat variation of the electrocardiogram exceeds that of blood pressure or cholesterol.

The six months repeat variation of cholesterol agrees well with the data in a recent review (Keys, 1969) 'With free-living, healthy men on a prescribed constant diet, repeated blood samplings extended over a period of two to six weeks have given average intraindividual SDs of 18 to $24 \mathrm{mg}$./dl.' The

TABLE 5 Predicted normal range (rounded) of intraindividual variation, in either direction, of selected electrocardiographic items within I hour and 6 months (all amplitudes in $0.1 \mathrm{mV}$ )

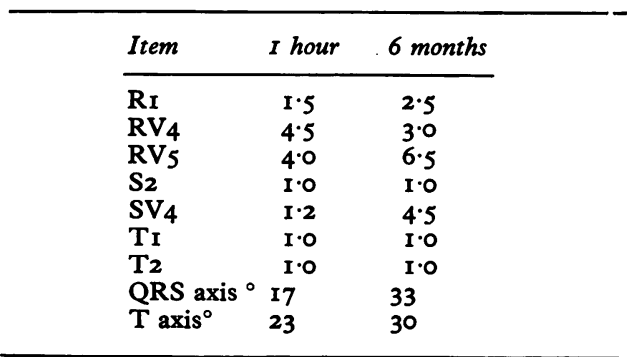


standard deviation for symptom-free coronary heart patients is somewhat higher (25-30 mg./100 ml.).

\section{References}

Kannel, W. B., Dawber, T. R., Friedman, G. D., Glennon, W. E., and McNamara, P. (1964). Risk factors in coronary heart disease. An evaluation of several serum lipids as predictors of coronary heart disease. The Framingham Study. Annals of Internal Medicine, 6I, 888.

Keys, A. (1969). Serum cholesterol and the question of 'normal'. In Multiple Laboratory Screening, p. 147. Academic Press, New York.

, Taylor, H. L., Blackburn, H., Brozek, J., Anderson, J. T., and Simonson, E. (1963). Coronary heart disease among Minnesota business and professional men followed fifteen years. Circulation, 28, 381.
- Aravanis, C., Blackburn, H. W., van Buchem, F. S.P., Buzina, R., Djordjevic, B. S., Dontas, A. S., Fidanza, F., Karvonen, M. K., Kimura, N., Lekos, D., Monti, M., Puddu, V., and Taylor, H. L. (1967). Epidemiological studies related to coronary heart disease: characteristics of men aged 40-59 in seven countries. Acta Medica Scandinavica, Suppl. 460, p. 392.

Simonson, E. (1955). Electrocardiogram in coronary heart disease. Minnesota Medicine, 38, 871 .

(196I). Differentiation Between Normal and $A b$ normal in Electrocardiography. C. V. Mosby, St. Louis.

- Brozek, J., and Keys, A. (1949). Variability of the electrocardiogram in normal young men. American Heart Fournal, 38, 407.

-, Horibe, H., Okamoto, N., and Schmitt, O. H. (1966). Effect of electrode displacement on orthogonal leads. In Vectorcardiography-1965: Symposium held at the Long Island fewish Hospital, New York City, May 1965, p. 38. Ed. by I. Hoffman and R. C. Taymor. North-Holland Publishing Co., Amsterdam. 